\title{
Background Knowledge and Reading Teaching
}

\author{
Qian Huang \\ College English Department of Dezhou University \\ Dezhou 253023, China \\ E-mail: qqh@dzu.edu.cn
}

\begin{abstract}
For a long time, it has been thought that any reader can comprehend a text well if such factors as vocabulary and grammar are not beyond his knowledge. However, the reading effect seems unsatisfying, which poses a great challenge for reading teaching. In this paper, the author explores the reading process and applies the Schema Theory, in order to prove the important role of background knowledge in reading comprehension. Based on this discussion, suggested teaching methods are available for employing background knowledge in reading teaching.
\end{abstract}

Keywords: Reading comprehension, Background knowledge, Schema theory, Schema

\section{Introduction}

The ability to read is acknowledged to be the most stable and durable of the second language modalities (Bernhardt 1991). In other words, reading plays a vital role in second language acquisition. For a long time, reading was traditionally viewed as a bottom-up process in a word-sentence-passage sequence, in which readers decode the text and rebuild what the writer wants to convey. Accordingly, reading teaching becomes teaching of language points known as grammar and vocabulary. When students have problems in comprehending the text, they are told that they fail because of their poor grammar or limited vocabulary. Consequently, people are misled to believe that the only approach of an effective reading is enlarging vocabulary and mastering grammatical rules. Actually it is not so. During the late thirty years, researchers of foreign language reading show their doubt towards the traditional view on reading and reading teaching. Among them, Adams (1982), Carrel (1984), Hudson(1982), Levine \& Haus (1985), Johnson(1981,1982), Singer \& Donlan (1982), Steffenson \& Joag-Dev (1984), and Wilson (1986) did researches on schema theory and the role of background knowledge in reading process. In china, researchers such as Tan (1997), Yang (1995), Lai (1998) Hu (1999) have undergone the same exploration and study to aid their L2 teaching practice. Consulting those researches, this paper discusses the interaction between reading comprehension and background knowledge. It finally provides some effective methods to equip background knowledge in reading teaching, with its aim at improving reading teaching in an anti-traditional way.

\section{The Important Role of Background Knowledge in Reading}

\subsection{The Background Knowledge as a Pedagogical Term}

At a language teaching angle, background knowledge refers to one's previously acquired comprehensive knowledge or world knowledge and one's special knowledge on a certain subject. Comprehensive knowledge means learning either in or out of school and an accumulation of a variety of experiences.

\subsection{The Reading Process}

Transformational Generative Theory (Chomsky) asserts that reading comprehension begins at the smallest and simplest language units and each single word, sentence and passage carries its own meaning independently which has no direct link with the reader. As have been noted in the introduction of this thesis, reading is simply decoding. When decoding ends, reading comprehension is realized. In that case, if comprehension does not go on successfully, it is the reading material that causes the problem grammatically or lexically. This theory highlights the influence caused by language structure more than the reader's own influence.

The recent researches indicate that reading comprehension is neither simply a unidirectional information-receiving activity nor a comprehension of words, sentences, and texts. Readers construct a certain cerebral mode in the reading process, a comprehension-aimed, multi-stratiform, and interactive process that requires consistent inferring and 
guessing. A multi-stratiform process means that readers wield language knowledge of different levels (phonetic, syntactic, semantic, etc.). An interactive process means that a text affects readers through its words, content, and structure whereas readers apply their background knowledge to act on the text. What role does background knowledge play in reading process? The schema theory explains.

\subsection{Schema Theory}

According to schema theory, any text, spoken or written, does not by itself carry meaning. In reading, a text only provides directions as to how a reader should retrieve or construct meaning from previously acquired knowledge. Comprehending words, sentences, and entire texts requires the ability to relate the material to one's own knowledge. Effective reading is a combination of the non-visual information already stored and organized in the brain and the present visual information printed on the page.

1) Schema

Before preceding any further, the notion of schema must be defined. Schemas, or schema as they are sometimes known, have been described as "cognitive constructs which allow for the organization of information in long-term memory" (Widdowson 1983). Cook (1989) states, "the mind, stimulated by key words or phrases in the text or by the context, activates a knowledge schema" (Cook 1989:69). Widdowson \& Cook both emphasize the cognitive characteristics of schema that allow us to related incoming information to already known information. This covers the knowledge of the world, from everyday knowledge to very specialized knowledge, knowledge of language structures, and knowledge of texts and forms they take in terms of genre, and organization. In addition to allowing us to organize information and knowledge economically, schemas also allow us to predict the continuation of both spoken and written discourse. The first part of a text activates a schema, that is, calls up a schema, which is either confirmed or disconfirmed by what follows.

\section{2) Types of Schema}

Research on the theory of schema has had a great impact on understanding reading. Researchers have identified several types of schemata. Content schema, which refers to a reader's background or world knowledge, provides readers with a foundation, a basis for comparison (Carrell \& Eisterhold 1983; Carrell, Pharis \& Liberto 1989). Formal schema, often known as textual schema, refers to the organizational forms and rhetorical structures of written texts. It can include knowledge of different texttypes and genres, and also includes the understanding that different types of texts use text organization, language structures, vocabulary, grammar, level of formality/register differently. Schooling and culture play the largest role in providing one with a knowledge base of formal schemata. While formal schemata cover discourse level items, linguistic or language schemata include the decoding features needed to recognize words and how they fit together in a sentence. First language readers, through repeated examples, are able to generalize a pattern or guess the meaning of a word, which may not have initially been part of their linguistic schema. The building of linguistic schema in a second language can proceed in the much the same way.

From the above discussion it is evident that schema plays an important role in text comprehension, both in the L1 and L2 context. For example, whether reading in a first or second language, one can assume that both native and non-native readers will understand more of a text when they are familiar with content, formal, and linguistic schema. An L2 reader, however, who does not possess such knowledge can experience schema interference, or lack of comprehension-ideas which are examined further in the following discussion pertaining to relevant research in this area.

\section{3) Content Schema and Background Knowledge}

Content schema or cultural orientation in terms of background knowledge is also a factor that influences L2/FL reading and has been discussed by Barnett (1989), Carrell and Eisterhold (1983), and Johnson (1982). Most methodologies investigating the role of schemata or background/prior knowledge were variations on Carrell's (1987) paradigm. This study involved 28 Muslim Arabs and 24 Catholic Hispanic ESL students of high-intermediate proficiency enrolled in an intensive English program at a Midwestern university. Each student read two texts, one with Muslim-oriented content and the other with Catholic-oriented content. Each text was presented in either a well-organized rhetorical format or an unfamiliar, altered rhetorical format. After reading each text, the students answered a series of multiple-choice comprehension questions and were asked to recall the text in writing. Analysis of the recall protocols and scores on the comprehension questions suggested that schemata affected the ESL readers' comprehension and recall. Participants better comprehended and remembered passages that were similar in some way to their native cultures, or that were deemed more familiar to them. Other studies have shown similar effects in those participants better comprehended and/or remembered passages that weremore familiar to them (Ammon 1987; Carrell 1981; Johnson 1981, 1982; Langer, Barolome, Vasquez\& Lucas 1990; Shimoda 1989). Further evidence from such studies also suggested that reader's schemata for content affected comprehension and remembering more than did their formal schemata for text organization. For example in the Carrell's (1987) study described above, students remembered the most when both the content and rhetorical form was familiar to them. However, when only content or only form was unfamiliar, unfamiliar 
content caused more difficulty for the readers than unfamiliar form. Steffensen and Joag-Dev (1984) conducted a study using two descriptions of weddings both written in English. One was a description of an American wedding, while the other was of and Indian (subcontinent) wedding. Both the Indian students, for whom English was an L2, and the American students, for whom English was the L1, read the descriptions and were asked to recall the descriptions. It was found that readers comprehended texts about their own cultures more accurately than the other. While the readers indicated that the words were easy to understand, the unfamiliar cultural protocol of an Indian wedding made the passage more difficult to remember.

Johnson's (1981) study investigated the effects of the cultural origin of prose on the reading comprehension of 46 Iranian intermediate advanced ESL students at the university level. Half of the subjects read the unadapted English texts of two stories, one from Iranian folklore and one from American folklore, while the other half read the same stories in adapted English. The subjects' reading comprehension was tested through the use of multiple-choice questions. The recall questions and the texts were also given to 19 American subjects for comparison purposes. Results revealed that the cultural origin of the story had a greater effect on comprehension than syntactic or semantic complexity of the text. In another study, Johnson (1982) compared ESL students' recall on a reading passage on Halloween. Seventy-two ESL students at the university level read a passage on the topic of Halloween. The passage contained both unfamiliar and familiar information based on the subjects' recent experience of the custom. Some subjects studied the meanings for unfamiliar words in the text. Results of recall protocols suggested that prior cultural experience prepared readers for comprehension of the familiar information about Halloween on the passage. However, exposure to the unfamiliar words did not seem to have a significant effect on their reading comprehension. An interesting study was carried out by Kang (1992).Kang's study examined how second language readers filter information from second language texts through culture specific background knowledge. Korean graduate students with advanced English read stories and answered questions. A think-aloud protocol assessing their understanding and inferences indicated an effect of culture specific schemata and inferences upon text comprehension. Although all the variables and factors surrounding the issues of how culture shapes background knowledge and influences reading are not fully understood, there is agreement that background knowledge is important, and that content schema plays an integral role in reading comprehension. Overall, readers appeared to have a higher level of comprehension when the content was familiar to them. Given this, second language readers do not possess the same degree of content schema as first language readers, and hence, this can result in comprehension difficulties.

\section{Suggested Teaching Methods of Improving Reading Teaching through Background Knowledge}

To make sure that students could understand the material properly and quickly instead of being hindered by poorly applied background knowledge, a reading teacher should know the reading material well to make clear what background knowledge the students may lack, choose appropriate and effective methods inspiring students to make use of background knowledge in their reading comprehension, and assist students to incorporate visual information to their pre-existing background knowledge. In this way students could practice awareness and skills to apply background knowledge in reading comprehension, achieving a satisfying effect. Some effective teaching methods of this kind are available below.

\subsection{Class Discussion}

Class discussion is a traditional yet effective method. Discussion makes it possible for most students to participate actively and improve their oral English evidently. Group discussion is a better choice, for more students could open their mouth and state their own ideas. Firstly the teacher may give a well-designed topic related to the text. And then students discuss the topic in small groups, four or five students at the most, and present their group idea after discussion. The teacher may make a summary finally and lead in the text.

In the text "why I teach" (college English: Intensive Reading), the teacher may requires students to discuss the profession as a teacher as well as the teaching methods they like. From primary school to college students meet their teachers every day. In addition, some college students have experiences as an amateur teacher. So it is possible for all the students to state their own views. Based on reading and explaining the text, the teacher compares the author's idea and the students' ideas so that students could understand the text more than others.

\subsection{Writing and Presenting Personal Experiences}

A satisfying effect can be reached especially when students have a higher level of English, for they can express themselves orally or literally. This activity may begin either before or during handling the text. At the beginning students are given some key words or concepts. Then the teacher may explain the text related major points and pose some subjective questions such as "what do you think of ...?" "What makes you think of ..." etc. In answering those questions students are motivated to express themselves and incorporate the textual information to their knowledge base, and get their background knowledge strengthened. Or in another way students may choose short writing to express their ideas. Reading combined with writing is a good method if organized well. In the text "Big Bucks the Easy Way" 
(College English: Intensive Reading), students may talk about their own experiences when doing a part-time job. They may have an oral or written presentation. Comparing the text with their own experiences, students may understand the text easily. Meanwhile they can know more about American students and enlarge their previous knowledge base.

\subsection{Comparison between Native and Foreign Background}

It is also a traditional but well-accepted method, for comparison impresses students deeply and inspires a good memory. In the text "There's only luck" (College English: Intensive Reading), the teacher may make a comparison of the law of gun ownership between in China and in America, so that students can have an awareness of the different background and hence avoid understanding barriers. Also in the text "Big Bucks the Easy Way", as has been cited above, students may be aware of the independence of American people through comparing the different way that Chinese and American parents educate their children.

\subsection{Video and Slide Show}

Reading can also be equipped with multimedia like video and slide show. Psychologically students incline to accept visual and audio information. An active and creative teacher would exert multimedia as a main approach to display background knowledge directly and vividly. In the middle school English textbook there is a text titled "The earthquake". The teacher may make a video or slide show to display scenes when an earthquake happens, which plays an irreplaceable role in imparting background knowledge and helping students to understand the text easily. This is an example the author witnesses at a model English class competition that is worth imitating.

\subsection{Use of True-or-False or Multiple-choice Exercises}

Many textbooks arrange true-or-false or multiple-choice exercises to check the students' comprehension of the text. It is wise to make those exercises a good approach to check and teach background knowledge. Beyond that, the teachers are encouraged to create and compile more appropriate exercises to be an assistance of reading teaching. Exercises of this sort are more suitable for those students with strong comprehension but weak expression. In checking the answers, simply pointing out the correct answer is definitely not enough. The teacher should teach more than a single answer can afford.

\subsection{Guessing and Inferring}

The background knowledge permits the reader to provide coherence to the text, permitting better bridging inferences between non-coherent sections and also permitting additional elaborative inferences. We can see that background knowledge plays a vital role in making inferences in reading process. The teacher may select several key words which stand vitally in the text and require the students to infer what the text may talk about. With their assumption, students are impelled to read the text eagerly. This method needs additional work to select the key words elaborately and accurately.

\subsection{Widely Reading}

Except various background knowledge of different nations, human share a large amount of the same knowledge known as common knowledge that is beyond the limitation posed by culture, region, or religion. For example, one plus one equals two everywhere around the world. So students are encouraged to read as widely as possible either in English or in Chinese. Common knowledge is, to some extent, equally or even more important than language itself.

\section{Conclusion}

As a text is read, there is a large cognitive load on the reader as the reader is decoding the text and incorporating the textual information into his or her knowledge base. The key to incorporating the information into the reader's knowledge base is partly dependent on the amount of background knowledge of the reader. Having background knowledge will imply that the reader has a certain amount of knowledge of the subject of the text or related knowledge due to personal experiences and cultural background. A reader's background knowledge permits the information to be incorporated into pre-existing knowledge structures. Therefore readers who do not have an adequate amount of background knowledge on the subject of a text will have lower comprehension of the text (Spilich, Vesonder, Chiesi \& Voss 1979; Voss, Vesonder \& Spilich 1980). In conclusion, background knowledge plays so important a role in reading comprehension that any teacher cannot teach reading well without watching out for the background knowledge.

In this thesis some teaching methods are suggested, but they are far from enough. The author intends he readers of this thesis to create more and better methods to employ background knowledge in reading teaching.

\section{References}

Ammon, M. S. (1987). Patterns of performance among bilingual children who score low in reading. In S. R. Goldman \& H. T. Trueba (Eds.). Becoming Literate in English as a Second Language, pp. 71-105.

Barnett, M. A. (1989). More Than Meets the Eye: Foreign Language Reading Theory and Practice. Englewood Cliffs. NJ: CAL\& Prentice Hall. 
Carrell, P. L. \& J. C. Eisterhold. (1983). Schema theory and ESL reading pedagogy. TESOL Quarterly 17/4, $553-573$.

Carrell, P. L. (1981). Culture-specific schemata in L2 comprehension. In R. Orem\&J. Haskell (Eds.).

Carrell, P. L. (1984). The effects of rhetorical organization on ESL readers. TESOL Quarterly 18, 441-469.

Carrell, P.L, B. Pharis, \&J. Liberto. (1989). Metacognitive strategy training for ESL reading. TESOL.

Carrell, P.L. (1987). Content and formal schemata in ESL reading. TESOL Quarterly 21, 461-481.

Connor, U. (1996). Contrastive Rhetoric: Cross-Cultural Aspects of Second Language Writing. Cambridge: Cambridge University Press.

Cook, G. (1989). Discourse in Language Teaching: A Scheme for Teacher Education. Oxford: Oxford University Press.

Goodman, K. (1996). On Reading: A Common-sense Look at the Nature Language and the Science of Reading .Portsmouth. NH: Heinemann.

Norwood, NJ: Ablex.

Quarterly 23/4:647-678.

Selected Papers from the Ninth Illinois TESOL/BE Annual Convention, First Midwest TESOL Conference, pp. $123-132$. Chicago: Illinois TESOL/BE. 